\title{
Miedos y vergüenzas en la investigación científica
}

\section{Resumen}

María Alonso*

Mi vida atraviesa mi investigación, eso supone que las emociones que se desprenden de experiencias, pensamientos, deseos, en los que me veo involucrada a diario, están volcados en ella de alguna manera. Sin embargo, un espacio serio y riguroso como el de la ciencia, no puede verse contaminado por el mundo de los sentimientos, generadores de subjetividad e imparcialidad. $Y$ es que, todo ello se da cuando lo realmente relevante son los resultados. No obstante, para mí, desde la etnografía feminista, los resultados no son lo más importante. Lo que me resulta interesante es el proceso.

La cuestión es que yo también me he formado y me he construido en un mundo en el que lo relevante era "la verdad" de la ciencia. De manera que cuando me pongo a investigar sobre mi intimidad y la de otras -pues intento averiguar desde nosotras, si las parejas de lesbianas se construyen como relaciones de género- me doy de bruces con las emociones y afloran mis miedos y vergüenzas al dudar, yo misma, de la validez de mi investigación. emociones

Palabras clave: subjetividad- autoetnografía feminista- lesbianas-

\section{Fears and shames in the scientific investigation}

\section{Abstract}

My investigation flows through in the events of my life. Consequently, my daily emotions, thoughts, desires are somehow involved in my research. Nevertheless, a serious and rigorous area as science, it should not be contaminated by feelings that generate subjectivity and impartiality. All this happens when the results are important. However, since I am writing from the feminist etnography, I am not really interested in the results but in the process.

The fact is that I have been also educated thinking that the important thing was "the truth" of the science. So that, when I investigate through in my intimacy and that of others -since I am trying to find out if the lesbians'couples

*UNIVERSIDAD DE GRANADA (ESPAÑA). Contacto: mariaalonsovidal@gmail.com

Alonso Vidal, María "Miedos y vergüenzas en la investigación científica" en Zona Franca. Revista del Centro de estudios Interdisciplinario sobre las Mujeres, y de la Maestría poder y sociedad desde la problemática de Género, №25, 2017 pp. 200-228. ISSN, 2545-6504

Recibido: 16 de junio, 2017; Aceptado: 10 de octubre 2017 
were constructed as gender relations- I came across my emotions, so my fears and shames come up and I doubt the validity of my research.

Keywords: subjectivity- feminist autoethnography- lesbians- feelingsemotions

\section{Introducción}

“La emoción es (...) un matiz afectivo que se extiende por todo el comportamiento, y que no cesa de cambiar en todo instante, cada vez que la relación con el mundo se transforma, que los interlocutores cambian o que el individuo modifica su análisis de la situación"

(David Le Bretón, 2013)

El paradigma científico positivista ha relegado las emociones al mundo de la biología, como si fueran instancias naturales y universales que no merecen mayor análisis cultural (Michelle Rosaldo, 1980; Catherine Lutz y Geoffrey White, 1986). Además, son postergadas al ámbito de lo privado, tradicionalmente atribuido a las mujeres, lo que aumenta su desprestigio. Por eso pareciera que las emociones nada pueden aportar a un trabajo científico, pues son generadoras de imparcialidad,

"lo científico y aceptado por la academia era contemplar a personas (investigadores) que querían estudiar a otras personas sin ser humanas ellas mismas, y ocultando y negando protagonismo y elemento de reflexión a unos componentes tan específicamente humanos, y tan constitutivos de las relaciones sociales como son los sentimientos y las emociones" (Juan Antonio Flores, 2010:13).

Esto sucede cuando se pretende separar cuerpo y mente, como instancias independientes, y el acento se pone en encontrar un resultado 
neutral y objetivo, menospreciando aspectos como la subjetividad de quien investiga. Sin embargo, desde la década de los ochenta las emociones son abordadas por la antropología como experiencias construidas socialmente ${ }^{1}$, que constituyen la realidad corporeizada del sujeto -Michelle Rosaldo (1980) afirma que las emociones son pensamientos encarnados- $y$ se ponen de manifiesto en las relaciones sociales (Le Breton, 1999). $\mathrm{Y}$ es que, "las personas experimentamos afectivamente los acontecimientos de nuestras experiencias" (Juan Antonio Flores, 2010:12) Es por eso que a mí, desde la antropología y, concretamente, desde la etnografía feminista y colaborativa ${ }^{2}$, lo que me resulta realmente interesante, es el proceso. $Y$ considero fundamental tener en cuenta las emociones dentro de mi proceso etnográfico -tanto las mías, como las de mis iguales, como las de ellas conmigo-, porque me hacen llegar a cuestiones que de otra manera no podría.

Sin embargo, yo también me he formado en un mundo positivista en el que lo importante era "la verdad" científica. De manera que cuando me pongo a investigar sobre lo personal y manejo emociones, entonces, aparecen mis propias contradicciones, más emociones, que son mis miedos y vergüenzas, al dudar yo misma de la validez del proceso.

\footnotetext{
${ }^{1}$ Me centro en la antropología por ser la disciplina desde la que escribo. Sin embargo, la sociología ya trabajaba antes que la antropología con las emociones, desde la certeza de que las emociones tienen sentido en el ámbito de las relaciones sociales.

${ }^{2}$ Lxs profesorxs Aurora Álvarez y Gunther Díez (2014) entienden que con la la etnografía colaborativa se pueden superar los binomios jerárquicos de las epistemologías cartesianas objeto-sujeto de estudio, por ejemplo-, de modo que se desdibujan fronteras como investigadxr/investigadx. Se utilizan metodologías participativas que favorecen la producción de conocimiento desde abajo. Producir saberes por medio de un proceso de subjetivación de todxs Ixs miembrxs de la investigación es fundamental en este tipo de etnografía; partiendo de una política de localización, del papel de la subjetividad atravesada por nuestra experiencia a la hora de construir conocimiento. Por todo ello, lo más importante, nunca pueden ser los resultados, sino el proceso, donde se van a introducir tensiones, vulnerabilidades, etc., usando la reflexividad como propio proceso para producir la investigación.
} 


\section{Miedos y vergüenzas}

"El miedo forma parte de nuestra socialización del proceso por el cual se nos domestica como sirvientas temerosas del orden patriarcal"

(Itziar Ziga, 2009:18)

La investigación para mi tesis de doctorado me sumerge en el mundo de las relaciones lésbicas. Intento con ella averiguar si este tipo de parejas se construyen como relaciones de género ${ }^{3}$. Esta investigación parte de mí, de mis esquemas de pensamiento y, en función de ellos, de mi experiencia vital. Formas de pensar y actuar que vienen determinadas por la construcción de mi subjetividad como ser sexuado y generizado. $\mathrm{Y}$ es que, haber roto con ciertas normas, me sitúa a mí también en esos márgenes en muchos aspectos: mi vivencia como mujer; como lesbiana; por qué no, como feminista -desde el entendimiento de que los feminismos están denostados por muchos sectores de la sociedad heteropatriarcal; y como militante dentro de las diversidades afectivo sexuales. Así, mi yo como investigadora posicionada toma una serie de decisiones que van a determinar que la investigación llegue a unos lugares y no a otros. Elecciones que finalmente he hecho desde la consciencia de haber tomado una postura de resistencia epistémica y metodológica (Gregorio 2006) relativas al conocimiento denominado hegemónico.

Es por eso que el proceso no ha sido fácil en algunos momentos. He vivido conflictos éticos al enfrentar las creencias hegemónicas que tenía aprehendidas sobre el conocimiento científico, que me hacían dudar del valor

${ }^{3}$ Yo detectaba cierto desequilibrio en mis relaciones de pareja; un desequilibrio que podía asimilar al género, pero si utilizaba el concepto que define el género como la relación de superioridad estructural del hombre sobre la mujer, el paralelismo no era válido en el contexto lésbico donde no existen hombres. Posiblemente tuviera que buscar otro concepto en el que el sexo de las personas implicadas no fuera importante. Así lo hice, y me encontré con Joan Scott (1990), cuyo concepto me permite hacer un tipo de lecturas para las que el sexo/género de las partes integrantes dentro de una relación no es relevante. Aunque ese es un tema que excede este artículo. 
de mi forma de actuar -derivada de mi yo posicionado-, y me pedían hacer las cosas de una manera más democrática, con la intención de descolonizar el proceso de investigación. Y "de algún modo esta idea de la contradicción se ha ido situando en el centro de mi investigación" (Arribas 2011:787). De ahí que el proceso de toma de decisiones haya estado marcado por la aparición de miedos y vergüenzas, que unas veces me han paralizado, y otras me han hecho detenerme a reflexionar. Myriam Jiménez (2004) afirma que los esquemas de pensamiento, que a la vez son afectivos, nos orientan sobre situaciones emocionales, lo agradable o desagradable, por ejemplo, convirtiéndose las emociones en motivación y evaluación de las acciones. Por su parte, Renato Rosaldo (1989) afirma que es necesario considerar la posición del sujeto en el campo para entender los sentimientos que experimenta. Este lidiar con las emociones en mi investigación, me ha supuesto un gran esfuerzo en ocasiones, pero también me ha hecho aprender que, "los mecanismos de toma de decisiones están anclados en la capacidad de sentir afectos, y que la emoción es indispensable para la ejecución de los comportamientos racionales" (Damasio 1995 en A. Surrallés 2005). Por eso, estoy de acuerdo con Juan Antonio Flores (2010), y considero necesario analizar el impacto de las emociones en las relaciones que se dan en el campo, teniéndolas en cuenta, como un asunto epistemológico y metodológico de primer orden.

Paradójicamente he descubierto que la manera de encontrar otras formas de hacer, estaba en repensar la etnografía desde las epistemologías feministas y las investigaciones colaborativas -lugares en los que yo estoy posicionada ahora. Desde ahí reconozco el carácter parcial y situado del conocimiento científico que planteara Haraway (1991), dando importancia al saber que 
proporciona la experiencia comprometida y compartida. Una experiencia donde saber y emoción no son polos contrapuestos como el pensamiento occidental androcéntrico y etnocéntrico nos quiere hacer creer (Catherine Lutz y Geoffrey White, 1986), sino que para la construcción de conocimiento tienen valor por igual (Gregorio y Alcázar 2014).

Por todo esto, pensé abordar los miedos a los que me estoy enfrentando a lo largo del proceso investigador, porque son como fantasmas incómodos que me acechan en todo momento; entorpecen, limitan y me dificultan el trabajo (A. Surrallés 2005). Pero dudaba si hacerlo o no, porque son sentimientos muy personales. Y, ¿cómo saber si toda la subjetividad, incluso la más íntima, sirve en la construcción del conocimiento científico en el marco de las epistemologías feministas? Ana Alcázar (2014) dice que los sentimientos son una forma más de percibir el mundo y, por medio de la reflexividad emocional, podemos tener "un conocimiento más profundo acerca de nuestra implicación en el campo" (Spencer, 2010 en Ana Alcázar (2014:65).

En muchas ocasiones los miedos se vuelven vergüenza, y ¿quién quiere hablar de sus vergüenzas? En un seminario del Master Gemma (2015), la profesora invitada, Elena Casado, planteaba el tratamiento de este tema como algo relevante, y nos animaba a hablar de nuestras vergüenzas con naturalidad e incluso en tono irónico. Entonces me planteé, cuáles han sido mis vergüenzas en el proceso, y cómo las he gestionado. Aveces siento tanta vergüenza que todo me da vergüenza. Lo que se traduce, como decía, en que las cosas supongan el doble de esfuerzo. Otras veces, como se exponía en aquella clase, he preferido mentir a reconocer que sentía vergüenza. Vergüenza de la vergüenza o "el circuito de la vergüenza", lo denominó Elena 
Casado. Cuando he tardado muchísimo en llamar a una persona con la que ya había cerrado una entrevista porque sentía vergüenza, y le he puesto mil excusas por las que no lo he hecho ${ }^{4}$. Eso me hizo cuestionarme, cómo estoy interpretando y si lo estoy haciendo erróneamente desde una distorsión cognitiva de la realidad. Quiero pensar que en un paralelismo extraño con una investigación cuantitativo positivista, ese sería mi margen de error. No obstante, la interpretación no es el único mecanismo metodológico de esta tesis, y la triangulación (Comas, Pujadas y Roca 2010) por medio del apoyo en la teoría, en la observación participante, en las aportaciones de $1 \mathrm{xs}^{5}$ demás, me tranquiliza en ese sentido, porque creo que me ayuda a conseguir una "objetividad fuerte" (Harding 1996).

Siento vergüenza cuando pienso que sin ser antropóloga, ni siquiera socióloga, estoy haciendo una etnografía (Esteban 2004). Y ya no se trata de creer que estoy entrando en competencia con la disciplina, sino de la inseguridad de no hacerlo bien. Qué vergüenza. O que por desconocimiento, lo que haga o diga contrarreste alguna "ley fundamental" de esta ciencia. Por mucho que quiera, para abordar la tesis no puedo leerme todos los textos de una carrera y la bibliografía complementaria -y desde luego que lo he intentado; casi muero de estrés. Siento miedo de hacerlo mal y la vergüenza de la crítica ${ }^{6}$. No obstante, como decía, esto es una sucesión de toma de decisiones, decidí investigar desde aquí y tendré que asumir las consecuencias.

\footnotetext{
${ }^{4}$ Dolors Comas; Joan Pujadas y Jordi Roca (2010) advierten que un etnógrafo poco experimentado y tímido puede tener serias dificultades para comenzar una investigación.

${ }^{5} \mathrm{Me}$ decanto por el uso de la "x" para evitar detallar un género específico. Continúo con la misma dinámica a lo largo del texto.

${ }^{6}$ Jorge Simmel (1938) (en Gabriela Vergara, 2009) habla de la vergüenza como pudor, por hacer algo fuera de la norma que supone concentrar las miradas de Ixs demás en unx mismx.
} 
Y la primera fue lidiar con la autoetnografía como metodología para desarrollar la investigación ${ }^{7}$ (Gregorio 2014). "La autoetnografía es una modalidad de investigación etnográfica que utiliza los datos biográficos del investigador como datos primarios" (Joaquín Guerrero, 2014:237). A partir de ahí empecé a enfrentarme con otros modos de hacer. Como ya me avisara mi directora, se le iba a presuponer falta de rigor científico, dado el uso de la auto reflexividad y su consecuente subjetividad. Tener la certeza, de nuevo, de que me enfrento con la ciencia y a la academia positivista me daba miedo, pero era más personal el miedo a estar expuesta que se deriva de escribir una autobiografía, porque soy consciente de que estoy derramada en sus páginas (Esteban 2004). No suelo tener demasiado problema en hablar de mi vida, sobre todo si me sirve para construir conocimiento o reivindicar política y, en este caso, me sirve para ambas cosas. $\mathrm{Y}$ es que, con este método de investigación se politiza lo personal; de modo que, a través de la interpretación de la propia experiencia se puede interpretar el mundo social. Sin embargo, había una cuestión más allá, y es que la autoetnografía no sólo habla de quien escribe, sino de quien escribe y su relación con el mundo y con Ixs demás. Por eso, en no pocas ocasiones he sentido miedo de herir la sensibilidad de quienes aparecen en el texto porque no compartiéramos opiniones o estuviéramos interpretando cosas diferentes ante la misma situación. En esa

\footnotetext{
${ }^{7}$ Cuando le entregué a Carmen Gregorio (mi directora de tesis) un primer acercamiento a la investigación, yo llevaba la inseguridad de haber hecho una justificación en función de mi recorrido vital en el movimiento lgtb y mis relaciones lésbicas estables. Había intentado hacerlo de otro modo, pero las cuestiones que me surgían lo hacían siempre desde ahí, de observar y analizar tanto mis relaciones como las de quienes me rodeaban. Pensé, no obstante, que era fruto de mi inexperiencia como investigadora y que se corregiría con la práctica a lo largo del trabajo. Para mi sorpresa ella no me criticó que el texto fuera informal o personal. Al contrario, me animó a seguir por ese camino. En una segunda supervisión, a lo que ya dijera anteriormente, Carmen añadió, "según veo, María, definitivamente tu aportación va a ser una autoetnografía".
} 
línea he tenido conflictos éticos, cuando una persona me describía una situación con su pareja en la que yo detectaba una relación clara de poder pero ella no. Mi inercia era incluir esa información en la investigación pero, ¿cómo hacerlo, si ella está haciendo una interpretación diferente a la que yo hago de su experiencia? ¿Qué valía más lo que ella sintiera, nuestra relación o la propia investigación? Por eso he tenido miedo de incluir información que, de alguna manera, pudiera afectar a la vida de una tercera. Las consecuencias de esto vienen a la hora de la redacción ${ }^{8}$ del texto (Juan Garriga Zucal, 2012). A veces, me veo obligada a darle muchas vueltas a las narraciones de las participantes, seleccionando aquellos fragmentos que no las comprometan o las pongan en conflicto con sus parejas, por ejemplo, pero que me permita incluir sus argumentos sin que pierdan el sentido que ellas les dieron.

Aunque mi primera vergüenza, la que precede a todas y que se manifestó casi al principio, fue reconocer que percibía relaciones de poder en mis parejas. ¿Cómo era posible semejante cosa viviendo relaciones lésbicas ${ }^{9}$ y con mujeres feministas, además? Era bochornoso. Parece que es más políticamente correcto que las relaciones de poder se den entre Ixs heterosexuales: lo llaman relaciones de género y, al ser la norma, nadie se extraña cuando se habla de ellas; como mucho se piensa, "una más". En ese descubrimiento, sentía la vergüenza de estar ocupando la parte débil ${ }^{10}$, y el miedo de ofender a mi pareja

8 Juan Garriga (2012) describe varias situaciones de tensión en las que los participantes en su etnografía se mostraban bastante disconformes con la información incluida en el texto final, o la manera de redactarla, lo que le generó situaciones de miedo; puesta en peligro de los vínculos alcanzados durante el trabajo de campo y la reflexión de que las relaciones del trabajo de campo no terminan cuando unx se pone a escribir, sino que es entonces cuando empieza el diálogo antropológico, y se genera la tensión entre ambas partes.

${ }^{9}$ Yo venía del feminismo lesbiano que determinaba que las relaciones entre mujeres eran igualitarias porque no incluían hombres.

${ }_{10}$ Catherine Luzt y Lila Abu Lughod consideran que las emociones conforman al sujeto por medio del lenguaje y el discurso, y el discurso está, a su vez, vinculado al poder en sí 
que, por contra, quedaba ubicada en la dominante ${ }^{11}$-aunque el poder es bastante más complicado que ese planteamiento y no es posible profundizar aquí sobre el tema. Lo cierto es que, aunque mi pareja estaba de acuerdo en algunos aspectos, se rebelaba y justificaba nuestros comportamientos en otros. Su malestar hacía que yo, de nuevo, matizara mi argumentación en la redacción del texto, lo que dificultaba mi objetivo. Entonces, además de la vergüenza y el miedo, surgía también algo de enfado por mi parte. En cualquier caso, volví a sentir vergüenza cuando en otras relaciones, lésbicas o hetero, para mi sorpresa, mi postura había cambiado, y era yo quien se encontraba en el lugar de quien ejerce poder; yo que por esa idea simplista y binaria del fuerte sobre el débil, siempre me había pensado en el sector subordinado de la relación. Por otro lado, como decía antes, cómo reconocer públicamente que, de repente, yo ejercía poder, máxime, si al hacerlo exponía a quien tenía la relación conmigo y que "sufría a tiempo real” mi actuación. Qué vergüenza. De nuevo, mis emociones me indican cómo son interpretados socialmente los papeles que cada quien adquiere dentro de una relación de pareja.

mismo. Teniendo en cuenta que las emociones son parte de una forma de poder de género vinculado al discurso, estoy de acuerdo con las autoras cuando afirman que la ideología de género se relaciona con los discursos sobre las emociones, siendo expresiones de relación de poder. En esta línea, Eva Illouz (2007) desde la sociología, afirma que el capitalismo se construye desde una cultura emocional que transmite una manera de amar y trabajar muy concreta.Ésta es la que yo pienso que se da, al menos, en algunas relaciones lésbicas, dado que éstas son construidas e insertas en el heteropatriarcado capitalista, de ahí que interprete partes débiles y partes fuertes.

${ }^{11}$ Como explica Juan Antonio Flores (2010), han de tomarse las emociones como datos en sí mismos, como conocimiento relevante. El análisis de mi vergüenza por mantener una relación desigual, se convierte aquí en un aspecto central del significado cultural -la vergüenza como un modo de control social-, pues deja patente que en un contexto donde las relaciones lésbicas fueron construidas como igualitarias por una sección del feminismo lesbiano -precepto que, real o no, nosotras no cumplimos-, nuestra práctica cotidiana queda reprobada. Suspenden nuestras posiciones divergentes dentro de la relación de pareja -de ahí nuestras respectivas emociones. Así se pone de relieve la crítica que cierta parte del feminismo lesbiano hace sobre los roles y las relaciones de poder como reacción a una ideología heteronormativa dominante. De modo que, desde el análisis de las emociones puedo llegar a entender también cómo está estructurado el discurso y la sociedad. 
La siguiente cuestión me cuesta reconocerla. $Y$ es que he sentido vergüenza de hacer una investigación sobre lesbianas; pero no por ser lesbiana, sino porque el tema no fuera considerado científico, relevante o, simplemente, serio (Sáez 2006). O por una especie de homofobia interiorizada que me hace sentir vergüenza a hablar en ciertos ámbitos, el académico entre ellos, sobre un colectivo tan denostado. Extrañamente, no habría sentido vergüenza si el tema hubiera sido mujeres gitanas, inmigrantes o prostitutas incluso, y eso que todas vivimos en los márgenes ${ }^{12}$. Insisto en que el problema no es salir del armario $^{13}$, sino el tema de la investigación. Ha sido mucho más fácil hablar de él en contextos homosexuales o gayfriendly, donde me siento orgullosa de lo que hago, que responder en círculos heterosexuales y/o académicos a la pregunta, “¿y sobre qué es tu tesis?”. Y es que, sentía que no era formal tratar en la academia temas relacionados con asociacionismo (yo venía del movimiento LGTB), como no lo era hablar sobre lesbianismo en la universidad, es decir, tratar un tema tan denostado por el heteropatriarcado en una institución producto de ese mismo sistema y que, por supuesto, se rige por sus normas. Tras conocer a teóricos queer como Javier Saez (2006), Paco Vidarte (2010), Beatriz Preciado (2002), Lucas Platero (2008) o Gracia Trujillo (2008), me atreví a investigar desde, sobre, por y para las lesbianas -no necesariamente como colectivo identitario- con la intención de deconstruirlas y

${ }^{12}$ El análisis de mis emociones en relación con el contexto, me dice qué posición tienen estos colectivos en la estructura social y qué jerarquía hay entre ellos. No siento orgullo al analizar el lesbianismo, siento vergüenza porque estoy interpretando que está socialmente más reprobado que el resto y, de hecho, en el contexto académico lo está mucho más que en la calle. En cuanto a la relación entre orgullo y vergüenza, Anthony Giddens (1997)pone en tensión la dicotomía y llama la atención sobre el carácter social de la vergüenza que aparece, en este caso, por la interpretación de la opinión que tendrán Ixs demás sobre el lesbianismo -no por el lesbianismo en sí mismo.

${ }_{13}$ "Salir del armario" es una expresión en la jerga LGTBI que significa hacer visible voluntariamente la propia homosexualidad. 
analizarlas desde todos los primas posibles, contaminando las categorías hegemónicamente construidas, si era necesario. Rompí la frontera entre academia y movimientos sociales; como comprendí la relación entre el colectivo LGTBQI -en cualquiera de sus colectividades desagregadas- y el feminismo que, sorprendentemente, aún no había hecho.

Pero más allá de la universidad, me costaba hablar sobre mi tema de tesis con personas heterosexuales ajenas a mí o con tercerxs con quienes me siento vulnerable ${ }^{14}$, porque intuía que me iban a recriminar una temática vaga. Nunca pude imaginar que la gente estuviera tan interesada por los temas de investigación de quienes hacemos una tesis. Por supuesto, aquí todo viene unido. Primero me preguntan “¿y tú qué eres?” Una vez que he superado la vergüenza de pensarme desempleada o precaria, que le he dado a mi investigación el valor que se merece y respondo, "estoy haciendo latesis", acto seguido, viene irremediablemente la gran pregunta, " ¿y sobre qué?”. Comprendo que es un gesto de amabilidad interesarse por lo que hago y puede, incluso, despertar curiosidad pero, a veces, detesto tanto interés. Entonces respondo: "estoy estudiando cómo se construyen las relaciones de género en las parejas". No creo que mucha gente fuera de la academia comprenda el concepto "construir relaciones de género". Pero sí pienso que se acercan a la idea, "está estudiando parejas". Eso gusta, porque el amor

14 Cada vez me cuesta menos, por un motivo que es, cuanto menos, curioso. Mi actual relación con un chico hace que ahora tenga miedo a ser interpretada como heterosexual -a veces siento que hasta me rebelo contra eso. De modo que, en cuanto tengo oportunidad, me presento como bisexual. Hondeo la bandera del lesbianismo y cuento orgullosa sobre qué hago mi tesis. Esto puede tener otra lectura, que me cuestiono en ocasiones, y es que, se interprete que ahora tengo menos que perder porque no dejo de estar en el lado mayoritario y cómodo de la norma, el del reconocimiento, e independientemente de lo que yo diga, ser vista como "la heterosexual que investiga lesbianas". 
siempre vende. Por eso, inmediatamente, la respuesta que sigue es, "iqué interesante!". Y la situación concluye con una sonrisa hipócrita por mi parte, y la frase "¿Verdad? A mí también me lo parece. Me gusta mucho”. A veces me he preguntado, qué habría pasado si al tema con el que describo mi trabajo, le añado la coletilla “de lesbianas". Lo primero que veo es la cara de mi madre ella suele ser con quien me mido el pulso continuamente. Si después de tres años y medio sin trabajar -sin estar empleada, hablando con propiedad-, le digo que estoy haciendo una tesis sobre lesbianas, esto es, que no voy a descubrir la teoría de la relatividad, ni a recibir el premio Nobel por lo que haga en mi investigación; se puede molestar un poco conmigo, dados sus niveles de preocupación por mi bienestar y el de mi hija, y preguntarme, por qué no me dedico a hacer algo que me dé de comer. Aunque no es mi madre la que más me asusta. Lo que me avergonzaba, realmente, era que pensaran, “ ¿se va a hacer doctora hablando de lesbianas?". Frente a este gran malestar, la etnografía colaborativa me dio la respuesta (Lassiter 2005 (en Cardús i Font 2006) al recordarme que desde aquí no se busca el prestigio de una carrera brillante, sino priorizar a Ixs participantes, Ixs sujetxs estudiadxs, que al final era mi objetivo último y que había perdido de vista gracias a tanta incertidumbre.

Una de las vergüenzas que más quebraderos de cabeza me han generado, a pesar de haber aparecido cuando ya tenía la investigación muy avanzada, fue abordar que el lado heterosexual de mi bisexualidad se estuviera imponiendo a mi lesbianismo. En principio no veía este tema como algo relevante, ya que pienso que las identidades son fluidas y la sexualidad es una opción que las personas elegimos en cada momento. Sin embargo, con el paso 
de los meses fue cogiendo peso y, como Raquel Lucas Platero (2013:49) explica, "si toda la vida has salido con chicas, y ahora sales con chicos, tus amigos te dicen "iqué cambio!” ¿No? Pueden decírtelo bien o mal, pero en todo caso es una sorpresa, porque entendemos que la sexualidad tiene cierta constancia, pero en realidad no es así. A mí, personalmente, me preocupaba cómo iba a ser vista por mi grupo de iguales y cómo esto podía influirme tanto en mi vida como en la tesis,

"La información obtenida en campo depende en buena medida de las relaciones con quienes nos las brindan, del lugar que lleguemos a ocupar en el grupo estudiado; pero, además, esa misma relación y los juegos de negociación por los que somos aceptados bajo tal papel y no bajo tal otro, la manera en que nuestros estudiados construyen nuestra figura, es materia de alta significación, uno de los ejes centrales que pone en perspectiva nuestros resultados" (Juan Antonio Flores, 2010: 16-17).

En el caso de las participantes bisexuales no tenía problema, porque mi situación es una realidad que contemplan. Pero sabía que hay mujeres que viven el lesbianismo de otra manera y que podían ver este deslizamiento de mi sexualidad como una deslealtad o una traición; y no al lesbianismo como movimiento político, pues siempre me he considerado lesbiana política ${ }^{15}$, sino a las lesbianas como seres conscientes de que no quieren hombres en sus vidas afectivo sexuales. No me equivoqué en mi preocupación en algunos casos. Hubo quien lo vio como una derrota: "pero, entonces, María, ¿te hemos perdido definitivamente?". Y en ocasiones -varias veces, de hecho-, me dijeron que ya

${ }^{15}$ Con la expresión "lesbiana política" intento poner de manifiesto que siempre he utilizado mi lesbianismo para luchar por el acceso a la igualdad social, tanto desde el feminismo como desde el movimiento LGTB. 
lo sabían, "de todas maneras, yo siempre he pensado que tú eras heterosexual". Biddy Martin (1992) retrata la escena de un fragmento del libro Are they women? (Due 1901), en la que un grupo de mujeres que se consideran "del tercer sexo", critican a otra mujer que antes formaba parte del mismo $^{16}$, pero que ya no, porque se había casado con un hombre: “...suponiendo que Fritz nunca fue en realidad una de ellas, que su pretensión de haber pertenecido al tercer sexo era un engaño. La dificultad que supone mantener una dimensión clara entre las integrantes verdaderas y las simuladoras, entre lo interno y lo ajeno" (1992: 111).Y esto es, precisamente, lo que a mí me preocupaba. Y la preocupación se tradujo en vergüenza a la hora de contar a las que consideraba mis iguales que tenía una relación con un chico. No sabía si me iban a seguir mirando de la misma manera. Este proceso lo viví con tristeza, como parte de un duelo. Pensaba que iba a ser interpretada como traidora. Además, iba a ser una batalla ganada por el sistema heteronormativo; y es que, tiempo atrás, yo misma le había concedido al sistema ese beneficio. En situaciones análogas había sentido rabia. Si bien es cierto que, con la teoría y el acercamiento al transfeminismo ${ }^{17}$, deshice ese

${ }^{16}$ Esta situación es muy recurrente y aparece, por tanto, reflejada también en el cine. En la película Go Fish (1994) de Rose Troche una de sus personajes es juzgada por sus amigas por haberse acostado con un hombre. En este "ser juzgada" entra a debate su lesbianismo.

17 El transfeminismo es uno de los considerados nuevos feminismos. El libro Transfeminismos, Epistemes y Flujos (2013), lo define como una corriente del feminismo que amplía los sujetos del feminismo a otras personas oprimidas por el sistema heteropatriarcal por cuestión de etnia, raza, nacionalidad, edad, discapacidad, clase, orientación, identidad, etc.-, más allá del sujeto mujer, pero incluyéndolas a ellas, por supuesto. De ahí que sean relevantes en esta corriente el colectivo LGTB y los movimientos trans. Desde el transfeminismo se entiende la interseccionalidad de las opresiones. Mi posicionamiento en este feminismo es porque desde aquí se entiende la identidad como algo fluido que me permite transitar por la sexualidad, utilizando una identidad estratégica. Así, salí de las políticas identitarias en las que estuve militando durante años, pero cuyas reivindicaciones nos abocaban a una asimilación heteronormativa con la que no termino de estar de acuerdo, pues si bien creo en la igualdad, creo más en la integración de una diversidad igualitaria. Desde aquí puedo interpretar el género como un sistema relacional de poder. Además, no se entienden 
argumento. Pero pude hacerlo porque trabajaba asiduamente con estos temas a nivel teórico y desde el feminismo, lo que me daba amplitud de miras. Entiendo que mi entorno no tenía por qué estar en el mismo posicionamiento que yo. O aunque lo hiciera, no compartirlo. Los posicionamientos son importantes.

Además tenía en mi contra que la bisexualidad ha estado históricamente tan marginada entre nosotras, que no sabía hasta qué punto la aceptación era real o sólo una postura social. Así que, sentía miedo de que me excluyeran de esa complicidad que yo siento entre las lesbianas, que reconozco y que tanto me gusta. Finalmente, decidí contarlo-con cuenta gotas y seleccionando a las personas a las que se lo decía. Las reacciones fueron mucho más transigentes de lo que yo había augurado ${ }^{18}$. Supongo que la credibilidad que me aporta haber estado media vida militando activamente en el colectivo LGTB; seguir haciéndolo, aunque no sea desde el movimiento institucional; investigar sobre lesbianas durante años y ser feminista, hicieron que la sospecha fuera menor. De modo que, los resultados no fueron los que había pronosticado. No había tenido en cuenta aspectos como que para algunas de mis iguales las categorías no son importantes. Vivir en un mundo sin categorías o con las mínimas posibles, nos hace más libres. $U$ otros motivos más personales o afectivos, como que me quieren y quieren para mí lo que me haga más feliz.

Sin embargo, a pesar de todo o antes de que mis pronósticos se derrumbaran, yo seguía sintiendo miedo y vergüenza en el espacio donde la masculino o femenino puede darse en cualquier cuerpo, entendiendo el cuerpo como el lugar desde el que se performa género y se materializa la normatividad.

${ }_{18} \mathrm{Si}$ bien hay quien no pierde oportunidad de recordarme que volveré al redil de las mujeres más temprano que tarde, porque “¿qué hace una tía como tú con un hombre?”. 
frontera entre lo personal y la investigación se diluyen. $Y$ es que toda esta situación tambaleaba mi papel como investigadora: el hecho de que yo como investigadora me sienta parte del nosotras, o sea, mujer, lesbiana y parte del grupo que construye conocimiento conmigo ${ }^{19}$, es decir, mi sujeto de estudio. Habiendo sido parte del grupo y habiendo sido aplaudida por decidir estudiarnos, ahora, de repente, salgo del grupo -o así puede ser percibido-, y en una lógica binaria, en la que o eres buenx o malx; opresxr u oprimidx; heterosexual u homosexual, yo puedo ser interpretada como heterosexual= opresora= mala. $\mathrm{Y}$ ser mirada con sospecha. De hecho, imagino muchas preguntas (tal vez me las hago yo misma como sujeta investigada que soy) desde mi subjetividad sesgada (posiblemente yo esté mirando con una distorsión más binarista que ninguna): ¿salir del grupo significa no querer estudiarlo ya? ¿Si ya no forma parte, qué interés iba a tener en estudiarlo? ¿Ahora somos nosotras (lo otro) y tú? O ¿todas seguimos siendo nosotras? ¿Y si tú también formas parte del nosotras, cómo es que mantienes relaciones con hombres? ¿Mantener una relación heterosexual no te hace perder la perspectiva al moverte en el mundo cómodo de la normalidad? Con estos pensamientos que me abordaban, ¿con qué credibilidad me presentaba como investigadora frente a las lesbianas a las que consideraba mis pares?

No obstante, llamarme lesbiana política ${ }^{20}$, practicando la bisexualidad

${ }^{19}$ Soy consciente de que mi preocupación surge ahora por mi relación de amistad con ellas, porque no me importaría tanto lo que pensara gente que me es ajena, que son extrañxs para mí. De nuevo, es tangible la construcción de la emoción en el marco de las relaciones sociales y como respuesta a una situación específica en un contexto determinado.

${ }^{20}$ Se trata de una reivindicación política cerca del concepto de lesbiana de Monique Wittig en el "Pensamiento Heterosexual" (2006). El grupo transfeminista Medeak en el año 2003, decide reivindicar el lesbianismo, no porque fueran lesbianas, sino porque lo consideraban como una categoría política necesaria. "Cualquiera de nosotras está dispuesta a identificarse como lesbiana, del mismo modo que muchas lesbianas se identificaron durante 
desde el lado heterosexual, también me fue criticado. Hay mujeres que consideran el lesbianismo un estilo de vida, no solo política. $Y$ en este contexto era donde mis argumentos perdían valor. No obstante, un día leyendo a Paco Vidarte (2007), sus palabras, sin pelos en la lengua, como él mismo manifiesta, me dieron una respuesta: "Hablamos su lenguaje perfectamente, nos lo enseñaron de chiquititos; pero somos bilingües y tenemos un idioma propio que a ellos les resulta incomprensible, bárbaro. No hay nada que explicarles. Nosotras nos entendemos. Y si les traducimos a cada paso lo que hacemos, probablemente les sonará ridículo, inconsistente, infundado. No es nuestra la tarea de traductores" ((2007:38). Vidarte habla de ellxs y nosotras, y pone la clave en el lenguaje común que nos une en la diversidad afectivo sexual, que para mí es una forma de pensamiento, una forma de entendimiento, y que, definitivamente, me hace ser una más entre nosotras.

En la línea de la explicación de Vidarte hay algo más. Siempre pienso en las amigas heterosexuales cuando planteo este tema. Ellas hacen de forma esporádica "noches de chicas sin chicos"; una actividad que suele resultar muy agradable y motivante porque les sirve para reforzar lazos, complicidad y confianza o semejante. Sin embargo, no son más que eso, ratos; y por eso, suelen servir más de esparcimiento, desahogo, que de reflexividad conjunta. Lo que para ellas es un acontecimiento para nosotras es la norma. Vivimos así, en un mundo mayoritariamente de mujeres, en el que unas formamos parte de la cotidianidad de otras y viceversa. ¿Qué implicaciones tiene esto para la

años con la mujer blanca heterosexual en la lucha por el derecho a abortar, la anticoncepción o el divorcio", afirma Itulturrioz miembro de Medeak en el artículo "El transfeminismo callejero de Medeak" de la revista Diagonal. 
metodología feminista? Marcela Lagarde (1990) denomina "estancia con las mujeres" a una de las técnicas utilizadas en la investigación para su tesis, Cautiverios de las Mujeres Madresposas, monjas, putas, presas y locas (1990), que consistió en imbuirse en la vida de las mujeres, "fue la vía de investigación más importante... estar con las mujeres para aproximarse y analizar sus vidas, consiste en compartir con ellas, hacer cosas juntas, mirar y mirarse... acompañarse y participar en sus quehaceres, en sus actividades especificas, en situaciones de conflicto o de gozo, en la soledad de sus celdas" (1990:54). La cuestión es que, lo que para ella es buscar el momento, los espacios para estar con las mujeres y estudiarlas -a ellas, como si fueran lo otro-, yo no tengo que hacerlo, porque la convivencia, el grado de relación de unas con otras, las relaciones, los lazos, las articulaciones son tan estrechas, que mi cotidianidad son ellas, somos nosotras, vivimos asi $^{21}$. Si a eso le añado que la mayoría somos feministas y otras, sin categorizarse, se manejan muy bien en estas claves analíticas, resulta que el ejercicio de empoderamiento, pero más concretamente, lo que me trae hasta aquí, la generación de conocimiento, es algo que hacemos juntas a menudo, antes incluso de que yo empezara a investigar. El campo de trabajo somos nosotras mismas, desde nosotras

${ }^{21}$ Creamos comunidad más allá de que estemos en parejas, y de ahí se desprende una sinergia.Yme reafirmo en que tiene que ver con la capacidad crítica, pero también con la ausencia de (hetero)hombres en nuestras vidas. El hijo de una amiga, curiosamente heterosexual, pero sin pareja desde que la conozco, le manifestaba a su madre que estaba preocupado porque no quería quedarse soltero como ella y todas sus amigas. Nosotras no estábamos solteras, pero más allá de que él no viera las parejas-por la presunción de heterosexualidad-, es que, realmente, no se detectan porque nuestras fronteras están diluidas, somos tanto amigas, hermanas, parejas, compañeras, muchas veces todo a la vez, y en otras las relaciones afectivo sexuales se disuelven en relaciones de amistad y viceversa, y los afectos mutan, se mezclan. La propiedad privada "es mi...",no es monolítica, sino, más bien fluida, y estamos constantemente aprendiendo a gestionar las posesividades, porque cambiamos de posición, ya eres pareja, que eres amiga, que eres cómplice, amante, proveedora o receptora de afectos, de recursos, de saberes o de haceres, según las circunstancias. 
mismas, mirándonos desde el extrañamiento de la autocrítica feminista constante. Por eso, aunque mis amigas no se plantearan ninguno de mis miedos y dudas, y todo fueran inferencias mías, para confirmar que seguía siendo parte de ese nosotras, desde que comenzara mi relación heterosexual, las incitaba aún más a hablar sobre temas de interés para nosotras, les pedía mucho más feed back que antes, las involucraba más en la investigación. Yo reforzaba el campo. Y funcionó. Porque con él nuestros vínculos lo hicieron también -es como si ahora fuera incluso más lesbiana que antes. A la vez la tesis avanzaba. De modo que, voy a intentar solucionar mi planteamiento tratando de salir del binarismo de las categorías heteropatriarcales lesbianismo/heterosexualidad; hombres/mujeres. $Y$ es que, para que se dé esta reflexividad mutua, esta complicidad del nosotras, tal vez sea necesaria la unión del feminismo y el lesbianismo, pero más allá de los presupuestos del feminismo lesbiano, más bien como lo plantea el transfeminismo, desde la fluidez de las identidades. $Y$ es que, hay feminismos que a veces olvidan la diversidad. Pero, además, aunque el lesbianismo nos proporcione la perspectiva de los márgenes, si no se analiza críticamente -o si la heteronormatividad ocupa la cotidianidad de las lesbianas-, no conlleva reflexividad posible. Supongo, entonces, que si sigo siendo lesbiana política y entiendo este "política" desde el transfeminismo, no voy a dejar de formar parte de mi grupo de iguales, ni salir de mi campo de trabajo, ni ser vista como lo otro, aunque me toque eliminar cualquier ápice de sospecha dirigida a mí.

En otro orden de cosas, más relativas a la forma que al fondo, a veces, siento miedo al escribir. Escribir en un contexto autorreflexivo favorece el uso de la primera persona y un vocabulario y expresiones cotidianas. La segunda 
gran crítica por parte del tribunal ${ }^{22}$ a mi trabajo de $D E A^{23} i b a$ en ese sentido, el uso de expresiones demasiado coloquiales en el texto. En cualquier caso, no es la evaluación negativa a la metodología lo que me preocupa, sino la crítica que surge de ella la que provoca mi vergüenza, de nuevo, por miedo a ser minusvalorada al escribir de forma poco rigurosa y, ante esto, la preocupación obsesiva de no hacerlo bien. Aurora Álvarez y Gunther Díez (2014) hablan de reformular la gramática etnográfica, por ejemplo, produciendo nuevas narrativas.

Mi propósito último es que de aquí salga un texto accesible para las lesbianas, independientemente de la edad que tengan, clase social, nivel de formación o disciplina de la que vengan (Arribas Lozano, 2015), máxime cuando ha sido construido con las aportaciones de tanta gente. Pretendía conseguir un texto que sintiéramos nuestro, en el que nos viéramos reflejadas de alguna manera, pero que también nos sirviera para cuestionarnos, autocriticarnos y seguir generando debates nuevos que no nos dejen vivir en la inercia, sino siendo conscientes de hacia dónde vamos y por qué. Un documento con el que aprender, para crecer como personas individuales, pero también como colectivo que está en el ojo de mira de la mayoría no homosexual. Por eso mi aportación como investigadora, siguiendo a Susana Narotzky (2004), viene desde la ética asociada con el compromiso político -

${ }^{22}$ La primera me alertaba sobre la imposibilidad de hacer una investigación con gente de mi círculo más cercano. "No va a hacer una tesis sobre sus amigas", me dijeron. Ese ha sido un gran lastre para mí a lo largo de todo el proceso. Aunque las conversaciones con Carmen me ayudaron a comprender que lo importante de mis amigas era la experiencia que tuvieran ellas como lesbianas y no tanto su relación conmigo, hecho que en una investigación positivista sería relevante si buscaba la objetividad, pero que no lo es desde donde yo escribo, desde las subjetividades.

${ }^{23}$ El Diploma de Estudios Avanzados es el título que nos otorgaban en el antiguo plan de estudios de doctorado en España al realizar y defender el trabajo de tesina -lo que antes denominé "Suficiencia Investigadora"- que, entonces, era previo al trabajo de tesis. 
entendido como progresista-, esto es, desde la intención consciente de que esta investigación suponga un apoyo a la transformación social en positivo para el colectivo lésbico. Lo que conllevaba que haya buscado los espacios de encuentro que favorecieran la generación de conocimiento. Un conocimiento que supone la información como variable a tener en cuenta a la hora de tomar decisiones en nuestras vidas. De modo que yo simplemente sería una guía para que las lesbianas, como grupo oprimido, podamos convertirnos en agentes de nuestro propio cambio.

Corriendo el riesgo de convertirme en demasiado ambiciosa, me gustaría que, más allá de nosotras, este texto pudiera leerse fuera de la academia para que, nuestros planteamientos y cuestionamientos, como el conocimiento construido, revierta en otros sectores. Que fuera una oportunidad para que otros sectores de la sociedad nos conocieran, sino "tal y como somos", porque no sé muy bien qué es eso, al menos que nuestras narraciones les permitieran pasear por planteamientos de vida, en algunos aspectos diferentes, en otros absolutamente iguales a los suyxs, pero casi siempre denostados por desconocimiento. En mi cabeza está la imagen del libro en manos de mi madre -ya dije antes que con ella me mido el pulso- o mis hermanxs. Si ellxs pueden leerlo sin aburrirse y comprendiendo lo que dice, entonces habré logrado mi objetivo.

Sea como fuere, para cualquiera de esos propósitos, y volviendo al lenguaje, es necesario que el texto sea accesible y ameno, porque un documento denso o farragoso no resulta atractivo y limita su lectura a ciertos ámbitos de la academia. Lassiter 2005 (en Cardús i Font 2006) destaca la importancia de escribir la etnografía de forma clara, correcta y comprensiva, 
evitando la jerga científica, que marca las relaciones de poder entre quienes están en la academia y Ixs que están fuera. Me gustaría romper con la idea de que la lectura fácil es sinónimo de un mal trabajo. Aunque hay algo que me inquieta, ¿qué se entiende por "correcto"?

Siguiendo con la escritura, ha sido revelador conocer el trabajo de Mercedes Blanco (2012), Nancy Sheper Huges (2010) o Ruth Behar (2011). Ellas usan un tipo de relatos literarios como textos válidos para la investigación científica y construcción de conocimiento (Gregorio 2006; Juan Antonio Flores, 2007). Con sus aportaciones han respondido a algunas de mis dudas de redacción y han favorecido que incluya en la tesis, sin miedo esta vez, el tono irónico, y narraciones que más se acercan al cuento corto, la poesía o a la novela que a un ensayo. Entendiendo que el contenido, como el momento autorreflexivo en el que fueron escritos, son perfectamente válidos para encontrar en ellos aspectos que considero relevantes de cara a despejar algunas de las incógnitas que me/nos inquietan. Para no alejarme demasiado de mis referentes, Monique Wittig me sirve de aval con su texto Cuerpo Lesbiano (1977), que en palabras de Meri Torras (2007), "está a caballo entre la teoría y la creación, la autobiografía y la ficción" (2007:14).

En este sentido, y desde la obsesión que tenía, casi desde el principio, por la validación científica de la investigación, en un intento por acercarme a todo tipo de formalidad escrita, incluso yo misma le he dado formato a los documentos -doble interlineado, alineación justificada y tipografía New Times Roman. Por eso, el día que Elena Casado puso la tipografía Comic Sand, como ejemplo de lo que para la academia se consideraba vergüenza -y repugnancia/rechazo- por considerarse poco rigurosa científicamente, "como si 
el fondo tuviera algo que ver con la forma", decía, me sentí identificada y muy reconfortada. Yo también había hecho un paralelismo entre estética y rigor, formalidad, seriedad y credibilidad. De hecho, reconozco que me cuesta quitarme ese sesgo, y cuando veo un texto con esa tipografía u otra semejante, hago un esfuerzo doble por prestarle atención y tomarlo en serio. En cualquier caso, nada garantiza, por supuesto, que un texto justificado, con tipografía Times New Roman e interlineado a uno y medio sea mejor en el fondo.

\section{A modo de conclusión}

Los sentimientos y emociones que surgen en el transcurso de una investigación tradicionalmente denominada "científica" han sido, por lo general, denostados y/o eliminados, ya que considera que forman parte de la subjetividad y contaminan la neutralidad de la ciencia. Sin embargo, cuando se cambia de paradigma, dejando a un lado el positivismo y acercándose a metodologías y epistemologías más democráticas y horizontales (en las que se tiene en cuenta el proceso investigador y no solo el resultado) entonces reconocerlos y utilizarlos en beneficio de la investigación parece la manera más eficiente de llevarla a término.

Por eso fue una sorpresa -y también un aprendizaje- cuando tuve la oportunidad de hacer mi autoetnografía y además, traer al texto la voz marginal de mis iguales. Se trataba de generar conocimiento desde nuestras propias experiencias, pensamientos y deseos, a los que yo les daba forma como investigadora, aunque también participara de ellos como persona investigada. De repente nuestras vidas estaban atravesadas por la investigación y ésta estaba conformada por nuestra subjetividad. Nosotras estamos acostumbradas 
a analizar la realidad porque, hacernos planteamientos críticos desde el extrañamiento para mejorar y transformar el entorno forma parte de nuestro estilo de vida feminista. Sin embargo, no pensamos que algo que forma parte de nuestra cotidianidad pudiera ser considerado conocimiento y tener valor de ciencia. Parece que las cosas se revalorizan cuando se llevan a determinados espacios formales o institucionales, como la academia. Así, lejos de terminar de aceptar que esto pudiera ser considerado científico, mis esquemas de pensamiento, aún moldeados por el positivismo, se han empeñado en plantearme no pocos cuestionamientos en cuanto a la adecuación o no de forma y fondo, poco normativos, de la etnografía, poniéndome constantemente en cuestión. En ese contexto han ido surgiendo otras subjetividades, miedos -y vergüenzas también-, producto de mi constitución como sujeto y de mis relaciones sociales en el campo, que me han dificultado avanzar. Y es que, no resulta fácil gestionar emociones en un espacio que se supone aséptico y donde no están permitidas.

Una vez que he reconocido y aceptado que los sentimientos y las emociones también forman parte de la etnografía, me han servido para activar procesos de autorreflexión más profundos, cuyo resultado he integrado enriqueciendo el conocimiento generado. Así, entiendo que ésta es la manera por medio de la que, al investigar no sólo se obtiene conocimiento de lo que se hizo sino también del cómo, para quién y desde dónde; aportaciones que considero relevantes.

\section{Bibliografía}

ALCÁZAR Campos, Ana (2014). "Siendo una más. Trabajo de campo e 
intimidad", en Revista de Estudios Sociales, Monográfico: Sexualidades e interseccionalidad en América Latina, el Caribe y su diáspora, 49, (pp. 60-71).

ALCÁZAR, Ana; Gregorio, Carmen (2014). "Trabajo de campo en contextos racializados y sexualizados. Cuando la decolonialidad se inscribe en nuestros cuerpos", en Gazeta de Antropología, 30.

ÁLVAREZ Veinguer, Aurora y Díez, Gunther (2014). "Etnografía colaborativa: coordenadas desde un proyecto en curso". En Actas XVIII Congreso de Antropología. Antropología y Descolonialidad, (pp. 3447-3471).

ARRIBAS Lozano, Alberto (2011). "Contradicción, Contingencia y Deseo. Micropolítica de (mi) investigación". En Actas XII Congreso de Antropología. Lugares Tiempos Memorias. La antropología Ibérica en el Siglo XXI, (pp.787791).

BEHAR, Ruth (2011). "De estos que no os olvidan". En Actas XII Congreso de Antropología. Lugares, Tiempos, Memorias. La antropología Ibérica en el Siglo XXI, (pp.195-210)

BETEMPS, Caroline y Fernández, June (2011). "El transfeminismo callejero de Medeak".

Diagonal.

https://www.diagonalperiodico.net/movimientos/transfeminismo-callejeromedeak.html

BLANCO, Mercedes (2012). "Autoetnografía: una forma narrativa de generación de conocimiento", en Andamios. Revista de Investigación Social, 9 (9), (pp.49-74).

CAMPS, Victoria (2011). El gobierno de las emociones, Barcelona, Ed. Herder.

CARDÚS Y FONT, Laura (2006). "Reseña de "Collaborative Ethnography de "Eric Lassiter Luke", en Liminar. Estudios Sociales y Humanísticos, 4 (2), (pp.133-137). México, Centro de Estudios Superiores de México y Centro América.

COMAS, Dolors.; Pujadas, Joan. J.; Roca i Girona, J. (2010). Etnografía, Ed. UOC., Girona.

DEL VALLE Murga, Teresa (2012). "El poder evocador como parte de la memoria", en Pelscamins de l'etnografia: un homenatge a joan Prat. (pp. 303311). Barcelona, Universitat Rovira iVirgili. 
ESTEBAN, Mari Luz (2004). "Antropología encarnada. Antropología desde una misma", en Papeles del CEIC, 12, CEIC

FERNÁNDEZ Prieto, Carlos (1997). "Figuraciones de la memoria en la autobiografía". En José María Ruiz Vargas, (Coord). Claves de la Memoria. Madrid, Ed. Rústica.

FLORES Martos, Juan Antonio (2010). "Trabajo de campo etnográfico y gestión emocional: notas epistemológicas y metodológicas, Revista Ankulegui, 14 (pp. 11-23).

GARRIGA Zucal, Juan (2012). "Josecito, te van a cargar a piñas...". Miedo y sentido común en el trabajo de campo", en Estudios de Antropología Social CAS/IDES, 2 (1), (pp. 15-24).

GIDDENS, Anthony (1997). Modernidad e identidad del yo. El yo y la sociedad en la época contemporánea, Ed. Península, Barcelona.

GREGORIO Gil, Carmen (2006). "Contribuciones feministas a problemas epistemológicos de la disciplina antropológica: representación y relaciones de poder", en AIBR. Revista de Antropología Iberoamericana, Ed. Electrónica, 1 (1) (pp.22-39). Antropólogos Iberoamericanos en Red.

GUERRERO Muñoz, Joaquín (2014). "El valor de la auto-entografía como fuente para la investigación social: del método a la narrativa", en AZARBE, Revista Internacional de Trabajo Social y Bienestar Social, nº 3, (pp. 237-242).

HARDING, Sandra (1996). Ciencia y feminismo, Madrid. Ed. Morata.

ILLOUZ, Eva (2007). Intimidades congeladas. Las emociones en el capitalismo, Madrid, Katz Editores.

JIMENO, Myriam (2004). Crimen pasional. Contribución a una antropología de las emociones. Universidad Nacional de Colombia, Bogotá.

LAGARDE, Marcela (1990). Cautiverios de las Mujeres Madresposas, monjas, putas, presas y locas, México, Ed. Universidad Nacional de México.

MARTIN, Biddy (2002). "La práctica sexual y las identidades lésbicas en transformación". En M. Barrett y A. Phillips, Desestabilizar la teoría. Debates feministas contemporáneos, (pp.107-131), México, UNAM.

NAROTZKY, Susana (2004). "Una historia necesaria: ética, policial y responsabilidad en la práctica antropológica", en Relaciones 98, (pp.109-145).

LE BRETON, David (2013). "Por una antropología de las emociones" en 
Revista Latinoamericana sobre estudios de cuerpo, emociones y sociedad, 10 (4).

LLAMAS, Ricardo (1998). Teoría Torcida. Prejuicios y discursos en torno a la homosexualidad, Madrid, Ed. Siglo XXI.

LUTZ, Catherine y GEOFFREY, White (1986). "The Anthropology of Emotions", en Anual Review of Anthropology, vol.15 (pp. 405-436).

PLATERO, Raquel (Coord). (2008). Lesbianas. Discursos y representaciones, Madrid, Ed. Melusina. (2013). "Marañas con distintos acentos: Género y Sexualidad en la Perspectiva Interseccional Entrevista con Raquel (Lucas) Platero", en ENCRUCIJADAS. Revista Crítica de Ciencias Sociales, 5, (pp.4452)

PRECIADO, Beatriz (2002). Manifiesto contrasexual, Madrid, Ed. Ópera Prima.

ROSALDO, Michelle (1980).Knowledge and Passion: IlongotNotion of Self and Social Life. Cambridge Uni- versityPress, Cambridge.

ROSALDO, Renato (1989). "Aflicción e ira de un cazador de cabezas”, en Rosaldo Renato, Cultura y Verdad. Nueva propuesta de análisis social, (pp. 1531), México, Ed. Grijalbo.

SÁEZ, Javier (2006). "Presentación del libro: Teoría queer. Políticas Bolleras, Maricas, Trans, Mestizas". Accesible en http://www.hartza.com/teoriaqueer.htm

SCOTT, Joan (1990). "El género: una categoría útil para el análisis histórico", en Lamas Marta, El género: la construcción cultural de la diferencia sexual, (pp. 265-302), México, Ed. PUEG.

SOLÁ, Miriam Y URKO-Elena (comp.) (2013) Transfeminismos. Epistemes, fricciones y flujos. Tafalla, Ed. Txalaparta.

SCHEPER-HUGHES, Nancy (2010). "Ira en Irlanda" en Margarita del Olmo. En Dilemas éticos en antropología. Las entretelas del trabajo de campo etnográfico. Ed.Trotta.

SURRALLÉS, Alexander (2005).“Afectividad y epistemología de las ciencias humanas", en AIBR. Revista de Antropología Iberoamericana. Número especial nov-dic. 
TORRAS, Mery (2007). "El cuerpo del delito. De la evidencia del cuerpo al cuerpo en evidencia". En Mery Torras (ed). Cuerpo e Identidad. (pp.11-36), Barcelona, Ed. UAB.

TRUJILLO, Gracia (2008).Deseo y Resistencia. Treinta Años de Movilización Lesbiana en el Estado Español (1977-2007). Madrid, Ed. Egales.

VERGARA, G. (2009). "Conflicto y emociones. Un retrato de la vergüenza en Simmel, Elías y Giddens como excusa para interpretar prácticas en contextos de expulsión". En Figari, C. y Scribano, A. (comps.), Cuerpo(s), Subjetividad(es) y Conflicto(s). Hacia una sociología de los cuerpos y las emociones desde Latinoamérica, (pp35-52), Buenos Aires, Ciccus Clacso.

VIDARTE, Paco (2010). Ética marica, Madrid, Ed. Egales.

WITTIG, Monique (1977). El cuerpo lesbiano, Ed. Pre-Textos, Valencia. (2006). Pensamiento heterosexual y otros ensayos, Madrid, Ed. EGALES. 